Revista Mexicana de Economía y Finanzas Nueva Época Volumen 14 Número 4, Octubre - Diciembre 2019, pp. 671-691 DOI: https://doi.org/10.21919/remef.v14i4.383

\title{
Comparison of the costs of the defined-benefit and the defined-contribution schemes under an actuarial methodology
}

\author{
Francisco Miguel Aguirre-Farías ${ }^{1}$ \\ Valuaciones Actuariales del Norte, México \\ Francisco Miguel Aguirre-Villarreal ${ }^{2}$ \\ Valuaciones Actuariales del Norte, México \\ José Daniel López-Barrientos ${ }^{3}$ \\ Universidad Anáhuac, México
}

(Recepción: 19/marzo/2019, aceptado: 24/junio/2019)

\section{Abstract}

The goal of this work is to use basic tools of actuarial analysis to prove for the first time that the cost of financing pure defined-benefit scheme is equal to that of a pure defined-contribution scheme whenever these plans grant equal benefits in terms of the amount and conditions to obtain them, and it is calculated using the same financial and biometric hypothesis.

We state our results in terms of an individual computation and of a group model (for in the second case, the defined-benefit scheme requires the calculation of a general average premium); and in both scenarios, we study the possibility of an early retirement with full and partial portability.

Our overall recommendation is to drop the discussion on which scheme is more expensive. The main limitation of this research is also its greatest asset: we have proven that there is no dominance of either plan over the other when there are no other labor market distortions; which means that the discussion could be in order should we consider the presence of such disruptions. 2010 Mathematics Subject Classification: 62P05, 91B02, 91B44, 91B15

JEL Classification: G220, H550, H750, J320

Keywords: Defined-benefit, defined-contribution, actuarial fairness, subsidiarity, actuarial balance

\section{Comparación de los costos de los sistemas de beneficio definido y de contribución definida bajo una metodología actuarial}

\section{Resumen}

El objetivo de este trabajo es utilizar herramientas básicas de análisis actuarial para demostrar por primera vez que el costo del financiamiento del esquema de beneficio-definido es igual al de un esquema de contribución-definida siempre que estos planes otorguen beneficios iguales en términos de cantidad y condiciones para obtenerlos, y llevamos a cabo nuestros cálculos usando las mismas hipótesis financieras y biométricas.

Enunciamos nuestros resultados en términos de un cálculo individual y de un modelo grupal (en el segundo caso, el esquema de beneficio definido requiere del cómputo de una prima media general); y en ambos escenarios, estudiamos la posibilidad de la jubilación anticipada con portabilidad total y parcial.

\footnotetext{
${ }^{1}$ Blvd. Galerías 200, Col. Villa Olímpica Ote., Saltillo, Coah., México. Tel. +52 (844) 416-1302 ext. 107 actuario@actuariales.com.mx.

${ }^{2}$ Blvd. Galerías 200, Col. Villa Olímpica Ote., Saltillo, Coah., México. Tel. +52 (844) 416-1302 ext. 140 faguirre@actuariales.com.mx.

${ }^{3}$ Facultad de Ciencias Actuariales, Universidad Anáhuac México. Av. Universidad Anáhuac, No. 46 Col. Lomas Anáhuac, Huixquilucan, Edo. de México. Tel. +52 (55) 5627-0210 ext. 8506. daniel.lopez@anahuac.mx.
} 
Resumen

Nuestra recomendación general es abandonar el debate sobre qué esquema es más caro. La principal limitante de nuestra investigación es también su mayor fortaleza: hemos demostrado que no hay predominio de ninguno de los planes sobre el otro cuando no hay otras distorsiones del mercado laboral; lo que significa que la discusión podría continuar vigente si consideramos la presencia de tales factores.

Clasificación JEL: G220, H550, H750, J320

Palabras clave: Beneficio definido, contribución definida, justicia actuarial, subsidiariedad, balance actuarial

\section{Introduction}

In practice, there are two pension schemes types; defined-benefit and defined-contribution. In the first case, the benefits are known in advance. In the second scheme, the only a priori knowledge is the amount of the individual contributions that are invested in a personal account, but the pension amount is defined until the moment of retirement, and it depends on the total amount of savings, the accrued interest, the life expectation of each person at the moment of his/her retirement and the commissions charged by the fund administrator. The main contribution of this paper is the proof that the cost of both types of pension plans is the same. We will also prove that if both schemes receive the same contributions, the granted benefits are equal.

Ever since the instalment of the first defined-contribution system in history, in Chile in 1981, there has been an endless debate as to what is the best choice for a pension scheme. In the past few decades we have seen several works stating that one of the schemes is better than the other, either for the employer, or for the worker (see, for example (Ali y Frank, 2019; Almeida y Fornia, 2009; Flores-Quiroz, 2007; Ilmanen, Kabiller, Siegel, y Sullivan, 2017; Johnston, Forbes, y Hatem, 2001; Milanés-García-Moreno, 2013; Organisation for Economic Co-operation and Development, 2015; Ortiz, Durán-Valverde, Urban, Wodsak, y Yu, 2019; Robbins, 2018; Senado de la República. Coordinación de Comunicación Social, 2016a, 2016b; Schrager, 2009; Williamson, Shen, y Yang, 2009; The World Bank, 1994) and the references therein). Nevertheless, when comparing both pension schemes, all of these works assume different hypotheses on either plan, and arrive to contradictory conclusions (for more on this issue, see the seminal works by Aguirre-Farías (see (Aguirre-Farías, 2012)), Barr (see (Barr, 2002)), and Diamond (see (Diamond, 2002)). In the words of the latter, "there is no simple dominance of one (scheme) over the other in the presence of other labor market distortions" (see (Diamond, 2002, p.57)), therefore it is necessary to set the context in which we compare the plans. In the case of the present research, we work with the cost of the plans from the points of view of the employee and the employer.

One of the reasons for the paradoxical disagreement between the authors resides in an assumption of some sort on the intergenerational solidarity. By this term, we mean that the contributions of the new generations are used to cover the benefits of the current pensioners. If this solidarity is not given, that is, if the savings of the new generation are not used to pay for the pensions already committed, a financial deficit with serious consequences could be caused, because the incomes generated by the current generation will decrease gradually until their extinction, and the transition cost could be greater than the cash flows (see (Aguirre-Farías, 2012, p.70) and (Instituto Nacional de las Personas Adultas Mayores, 2017)). It should be noted that the defined-benefit, the defined-contribution, and the mixed schemes can be funded or not. In the same way, these can maintain intergenerational solidarity or not. Breaking this solidarity is a very common proposal when planning a reform to current pension schemes (see, for example, the Mexican case (Senado de la República. Coordinación de Comunicación Social, 2016b)). In concrete, the modification consists in concentrating the contributions of the new generations in a different fund than that of the current generation.

There are arguments in favor and against conceiving intergenerational solidarity as a com- 
ponent of the so-called actuarial fairness principle (see (Bräutigam, Guillen, y Nielsen, 2017; Donnelly, 2015; Landes, 2015; Meneu, Devesa, Devesa, Domínguez, y Encinas, 2016)). This notion states that individuals should pay premia that reflect the risks they bring to the collectivity, and of course serves to establish a fair and adequate price for a given risk. Breaking intergenerational solidarity when there is a reform of a pension system implies a considerable increase of the transition cost in cash flows, and the difficulty of convincing the authorities to consider a reform (whom, besides the political implications, will have to assume the fiscal cost). However, if the debt is documented with the implied credit rating risk, this disadvantage can be solved by a long-term credit with low-interest rates. Besides, the rupture of intergenerational solidarity also yields that the scheme of the new generations will be financed, which from a technical point of view is highly recommended, i.e. this not only does not violate the actuarial fairness principle, but actually reinforces it. For this reason, we can place our work among those which assume that the intergenerational solidarity is broken.

Since ours is a methodological proposal aiming to present an analysis of each plan with actuarial tools, we believe that it contributes to the state-of-the-art in the direction of works such as (Diamond, 2002; Iyer, 1999; Knell, 2017; Meneu y cols., 2016; Organisation for Economic Co-operation and Development, Banco Interamericano de Desarrollo, y The World Bank, 2014; Poterba, Rauh, Venti, y Wise, 2007), for it deals with the theoretical cost of the schemes without the distortion of, for instance the political factor. In particular, as in (Organisation for Economic Co-operation and Development y cols., 2014), we do not wish to compare the plans to prove the superiority of either option above the other (clear counterexamples can be found in (Almeida y Fornia, 2009; Ilmanen y cols., 2017; Ortiz y cols., 2019) and (The World Bank, 1994)), but to report a description (and an equivalence) in view of the features of each scheme. However, our work fills an existent gap in the literature because, to the best of our knowledge, this is the first time when a proof on the equivalence of both schemes is presented in the individual and group frameworks.

The rest of the paper is divided as follows. In the next section we introduce and justify our main hypothesis; and in Section 3, we define the cost and benefits for an individual under either scheme, assuming that the collectivity does not allow new entries nor any exits (and that the intergenerational solidarity is broken). In Section 4 we relax this assumption and allow early retirements with partial portability. Section 5 is devoted to the analysis of the aggregated versions of the results presented earlier. We introduce our conclusions and emphasize our results in Section 6.

\section{Basic definitions and hypotheses}

We assume that both schemes meet the following assumptions.

- The same income rate (see Remark (i) below),

- the same retirement age (see Remark (i) below),

- the same contribution period (see Remark (i) below),

- the same salary and pension increase rate (see Assumption 2.1(i) below),

- the same interest rate $r$,

- the same tables of mortality, disability, rotation, etc. (see Assumptions and below),

- the biometric hypotheses used in the actuarial calculation are maintained constant over time (see Assumptions and below),

- there are no commissions nor administration costs,

- there is no accrued reserve for either plan (otherwise, it is assumed to be equal in both plans), 
- in the case of a termination without the right to a pension, both schemes consider, or not, lump sum withdrawals or roll-over to another pension institution for both, the employees' and employers' contributions, as well as the interests that these generate,

- the intergenerational solidarity is broken (see Assumption 2.1(ii) and Remark (ii), below).

Our main hypothesis intends to relieve the comparison from such distortions. It is the following.

(i) The annual rate of change of the payments (i.e., salary and pension) for a life aged $(x+k)$ equals $s$ for $k=0,1, \ldots$

(ii) The collectivities under consideration are closed and there is no transition cost between generations.

(iii) There exists a balance between the actuarial present values of the contributions and the benefits. That is, if $(A P V C)$ represents the actuarial present value of the contributions to a given pension fund, and $(A P V B)$ stands for the actuarial present value of the benefits; then

$$
(A P V B)=(A P V C)
$$

We set now a few pointers linked to this hypothesis.

(i) In all cases, the retirement age is (y). This means that, under Assumption 2.1(i), the estimated annual salary at the retirement age is given by:

$$
(E S)_{y}:=(E S)_{x}(1+s)^{y-x} .
$$

Observe that, at age $(x)$, the term estimated could be erased, for in that case, we deal with the actual salary -see (Bowers, Gerber, Hickman, Jones, y Nesbitt, 1997, Section 11.5.2). However, we do not make such distinction to keep the notation as simple as possible. On the other hand, since $s$ is a rate which is to be charged to the payments (rather than just to the salary), the pension itself will update its value by this same amount. That is, if $P_{y+k}$ is the benefit payable at age $(y+k)$, and $P$ is the (constant) income benefit rate (sometimes dubbed as replacement rate), then under Assumption 2.1(i),

$$
P_{y+k}=P \cdot(E S)_{x} \cdot(1+s)^{y-x+k} \text { for } k=0,1, \ldots
$$

It is worth to mention that the fact that we consider a constant (and known) rate of growth of the payments for the whole life period is due only to a matter of simplicity. The importance of the assumption is that we consider the same rate for all the schemes we take into consideration.

(ii) In practice, when an entity (v.g. a country, an enterprise or an employer) evaluates a pension scheme as an alternative to another (which is already in use), the analyst considers that only the new generations will be subjected to the reform; while the generations which are still contributing to the current scheme, or are already enjoying their retirement benefits, will remain in that scheme. The result is that the cost of the reform for the entity is always lower than the cost of making no reforms. However, the cost of maintaining the benefits (i.e. transition cost of the reform) for the current and the older generations continues to be assumed by the entity itself. In the present work, we are interested only in the comparison of the schemes; and not in who will be the entity in charge of paying for the transition costs (see (Aguirre-Farías, 2012, p. 67-76)).

We say that the groups are closed to state that new entrants are not considered in our analyses (cf. Section 5). 
(iii) We will make an extensive use of equation (1) along our results. It is a standard hypothesis in the literature of actuarial and financial mathematics (see, for instance (Bowers y cols., 1997, Chapter 6) and (Kellison, 2008, Chapter 5)), and we believe that it embodies the notion of actuarial fairness (specially for the aggregated versions of our results, shown in Section 5). It essentially states that the available resources for allocation are those which have been paid for.

We start our study with a definition concerning the notation that we use. (See (Bowers y cols., 1997, Chapters 3.2.2 and 10.2).) For a life aged (x), the probability of decrement due to the specific cause $j=1,2, \ldots, m$ before time $t \geq 0$ is denoted by the symbol ${ }_{t} q_{x}^{(j)}$. Likewise, the probability of decrement due to any cause before time $t \geq 0$ is represented by

$$
{ }_{t} q_{x}^{(\tau)}:=\sum_{j=1}^{m}{ }_{t} q_{x}^{(j)} .
$$

We also define the the probability that a life aged $(x)$ survives to every possible cause of decrement until age $x+t$, for $t \geq 0$ as

$$
{ }_{t} p_{x}^{(\tau)}:=\left\{\begin{array}{ccc}
{ }_{s} p_{x}^{(\tau)} \cdot{ }_{t-s} p_{x+s}^{(\tau)} & \text { for } & 0<s \leq t \\
1 & \text { for } & t=0
\end{array}\right.
$$

It is easy to see, from (4) and (5), that

$$
{ }_{t} q_{x}^{(\tau)}:=1-{ }_{t} p_{x}^{(\tau)} .
$$

In (4), we let the case $j=1$ be the death as cause of decrement, and we note that there might be other valid causes of decrement that allow a contributor to leave a pension fund with (a part of) the savings that he/she managed to raise (v.g. disability and death due -or not- to work risk, voluntary separation, and dismissal). Last, but not least, it is important for the authors to state that, even when we are well aware of the existence of comparative works (see for instance (Almeida y Fornia, 2009; Collinson, 2001; Poterba y cols., 2007)) that exemplify the situation of pension systems around the world, we have deliberately kept ourselves away from this kind of study to avoid a debate we consider to be unnecessary.

\section{Individual computation without exits}

The purpose of the first subsection is to obtain the income benefit rate ${ }^{d c} P$ and the annual contribution rate of the salary ${ }^{d c} c$ for an estimated annual salary of $(E S)_{x+k}, k=0,1, \ldots$ under the hypothesis of a plan with individual accounts. In the second subsection we will study the defined-benefit plans and see that these amounts equal their correspondents ${ }^{d b} P$ and ${ }^{d b} c$ if the parameters remain the same.

For the extent of this section, we use the following hypothesis. There is no uncertainty as to the fact that a life aged $(x)$ will contribute to its pension fund until attaining age $(y)$, that is $y-x-k p_{x+k}^{(\tau)} \equiv 1$, for $k=0,1, \ldots, y-x$. (On the notation.) In this work, it is very important to make a proper distinction between the phase of life that a life aged $(x+k)$ is experiencing.

- Indeed, if the life is in the savings phase, that is, if $k=0,1, \ldots, y-x$, then we will use ${ }_{k} p_{x+k}^{(\tau)}$ as the probability that a life aged $(x+k)$ continues to contribute to its pension fund for another $k$ years while it survives to all possible causes of decrements.

- The other stage we take into account is the aging phase, i.e. ${ }_{t} p_{y+k}^{(1)}$ for $k, t \geq 0$ is the probability that a life aged $(y+k)$ survives (to death) to age $(y+k+t)$ (in other words, the probability that a person beyond the age of retirement continues to perceive a pension benefit). It is possible to consider the survival of a widow(er) as well for this phase, however, for the sake of simplicity, we consider only a single life. 
Assumption can be rephrased by saying the following:

A life aged $(x)$ makes annual monetary contributions of $c \cdot(E S)_{x+k}, k=0,1, \ldots, y-x$ with certainty to its individual fund until it attains the retirement age $(y)$.

\subsection{Defined-contribution plans}

Let ${ }^{d c} c$ be the (known) annual contribution rate of the salary. We can find an expression for the actuarial present value of the contributions under Assumption. Let $r$ be the annual real rate of interest. Under Assumptions 2.1 and, the actuarial present value of the contributions made to the retirement plan for a life aged $(x)$ is given by:

$$
{ }^{d c}(A P V C)_{x}={ }^{d c} c \cdot(E S)_{x} \cdot \ddot{a} y-x,
$$

where

$$
\ddot{a} y-x:=\left\{\begin{array}{cc}
y-x & \text { if } \gamma=0, \\
\frac{1-\left(\frac{1}{1+\gamma}\right)^{y-x}}{1+\gamma} & \text { otherwise }
\end{array}\right.
$$

stands for the so called (certain) annuity-due at the interest rate given by $\gamma:=\frac{1+r}{1+s}-1$ (see (Kellison, 2008, Chapter 3.3)). The total present value of the contributions for a life aged $(x)$ equals the sum of the present values of the periodic contributions (see (Cunningham, Herzog, y London, 2006, Chapter 6.1.2)). That is:

$$
\begin{aligned}
{ }^{d c}(A P V C)_{x}= & { }^{d c} c \cdot(E S)_{x}+{ }^{d c} c \cdot(E S)_{x+1} \frac{1}{1+r} \cdot p_{x}^{(\tau)}+{ }^{d c} c \cdot(E S)_{x+2}\left(\frac{1}{1+r}\right)^{2} \cdot{ }_{2} p_{x}^{(\tau)} \\
& +\cdots+{ }^{d c} c \cdot(E S)_{y-1}\left(\frac{1}{1+r}\right)^{y-x-1} \cdot{ }_{y-x-1} p_{x}^{(\tau)} \\
= & { }^{d c} c \cdot(E S)_{x}\left[1+\frac{1+s}{1+r} p_{x}^{(\tau)}+\left(\frac{1+s}{1+r}\right)^{2} \cdot{ }_{2} p_{x}^{(\tau)}+\cdots+\left(\frac{1+s}{1+r}\right)^{y-x-1} \cdot{ }_{y-x-1} p_{x}^{(\tau)}\right] \\
= & { }^{d c} c \cdot(E S)_{x}\left[1+\frac{1+s}{1+r}+\left(\frac{1+s}{1+r}\right)^{2}+\cdots+\left(\frac{1+s}{1+r}\right)^{y-x-1}\right] \\
= & { }^{d c} c \cdot(E S)_{x}\left[1+\frac{1}{1+\gamma}+\left(\frac{1}{1+\gamma}\right)^{2}+\cdots+\left(\frac{1}{1+\gamma}\right)^{y-x-1}\right] .
\end{aligned}
$$

The second equality is due to (2), and the third one follows from Assumption . A substitution of the power series inside the braces of the last equality by $\ddot{a} y-x$ yields the result. We can find also an expression for the actuarial present value of the benefits under Assumption. Let ${ }^{d c} P$ be the income benefit rate for the pension. Under Assumptions 2.1 and, the actuarial present value of the benefits for a life aged $(x)$ is given by:

$$
{ }^{d c}(A P V B)_{x}={ }^{d c} P \cdot(E S)_{x} \cdot \ddot{a}_{y} \cdot\left(\frac{1}{1+\gamma}\right)^{y-x},
$$

where

$$
\ddot{a}_{y}:=\sum_{k=0}^{\infty}{ }_{k} p_{y}^{(1)}\left(\frac{1}{1+\gamma}\right)^{k}
$$

stands for the so-called (contingent) whole life annuity-due. (See (Bowers y cols., 1997, Chapter 5 ) and note that, since we consider the aging phase of the life, the only decrement we take into account is death. Recall that we represent this cause with the symbol $j=1$.) The next equality 
follows from the analysis in, for example (Bowers y cols., 1997, Section 11.5.4).

$$
\begin{aligned}
{ }^{d c}(A P V B)_{x} & =\left[{ }^{d c} P_{y}+{ }^{d c} P_{y+1}(1+r)^{-1} p_{y}^{(1)}+{ }^{d c} P_{y+2}(1+r)^{-2}{ }_{2} p_{y}^{(1)}+\cdots\right]\left(\frac{1}{1+r}\right)^{y-x} p_{y-x}^{(\tau)} \quad(11) \\
& ={ }^{d c} P \cdot(E S)_{x}\left[(1+s)^{y-x}+\frac{(1+s)^{y-x+1}}{1+r} \cdot p_{y}^{(1)}+\frac{(1+s)^{y-x+2}}{(1+r)^{2}} \cdot{ }_{2} p_{y}^{(1)}+\cdots\right]\left(\frac{1}{1+r}\right)^{y-x} \\
& ={ }^{d c} P \cdot(E S)_{x} \cdot\left(\frac{1+s}{1+r}\right)^{y-x} \cdot\left[1+\frac{1+s}{1+r} \cdot p_{y}^{(1)}+\left(\frac{1+s}{1+r}\right)^{2}{ }_{2} p_{y}^{(1)}+\cdots\right]
\end{aligned}
$$

The second equality follows from (3) and Assumption . Now substitute $\gamma:=\frac{1+r}{1+s}-1$ to obtain (9), and hence, the result. To compute the benefit income rate (resp. the annual contribution rate of the salary), we use Assumption 2.1(iii) to equal (9) and (7); and solve for ${ }^{d c} P$ (resp. ${ }^{d c} c$ ). Thus we will have proven the next result. Under Assumptions 2.1 and, the benefit income rate and the annual contribution rate of the salary are given by

$$
\begin{aligned}
{ }^{d c} P & =\frac{{ }^{d c} c \cdot(1+\gamma)^{y-x} \ddot{a} y-x}{\ddot{a}_{y}}, \text { and } \\
{ }^{d c} c & =\frac{{ }^{d c} P \cdot \ddot{a}_{y}}{(1+\gamma)^{y-x} \ddot{a} y-x},
\end{aligned}
$$

respectively. The fact that we base the latter result on our assumption on the actuarial balance between contributions and obligations implies that the amounts ${ }^{d c} P$ and ${ }^{d c} c$ reflect the actuarial fairness principle.

\subsection{Defined-benefit plans}

Let ${ }^{d b} P$ be the (known) income benefit rate for the pension. The next results are entirely analogous to Propositions, , and, respectively. Under Assumptions 2.1 and, the actuarial present value of the benefits for a life aged $(x)$ is given by:

$$
{ }^{d b}(A P V B)_{x}={ }^{d b} P \cdot(E S)_{x} \cdot\left(\frac{1}{1+\gamma}\right)^{y-x} \cdot \ddot{a}_{y} .
$$

Let ${ }^{d b} c$ be the annual contribution rate of the salary. Under Assumptions 2.1 and , the actuarial present value of the contributions made to the retirement plan for a life aged $(x)$ are given by:

$$
{ }^{d b}(A P V C)_{x}={ }^{d b} c \cdot(E S)_{x} \cdot \ddot{a} y-x .
$$

Under Assumptions 2.1 and, the benefit income rate and the annual contribution rate of the salary are given by

$$
\begin{aligned}
{ }^{d b} P & =\frac{{ }^{d b} c \cdot(1+\gamma)^{y-x} \ddot{a} y-x}{\ddot{a}_{y}}, \text { and } \\
{ }^{d b} c & =\frac{{ }^{d b} P \cdot \ddot{a}_{y}}{(1+\gamma)^{y-x} \ddot{a} y-x},
\end{aligned}
$$

respectively. We are now ready to establish our first main result. The proof of the first part is straightforward from Propositions and ; while the proof of the second item follows immediately from Propositions, , and. Its relevance lies in the fact that, to the extent of our knowledge, Theorem 3.9(ii) represents the first effort to show an equivalence between the costs of both schemes. Under Assumptions 2.1 and,

(i) ${ }^{d b} c={ }^{d c} c$, if and only if ${ }^{d b} P={ }^{d c} P$; and 
(ii) ${ }^{d b}(A P V C)_{x}={ }^{d c}(A P V C)_{x}$, if and only if ${ }^{d b}(A P V B)_{x}={ }^{d c}(A P V B)_{x}$.

A plausible rephrasing of Theorem 3.9 is that, when the first consequence holds, then by virtue of (7), (9); and (12)-(13), the second consequence holds as well.

\section{Individual computation with exits and portability benefits}

In this section, we use the following generalization of Assumption . A life aged $(x)$ does not necessarily reach the age of retirement $(y)$, that is

$$
{ }_{y-x} p_{x}^{(\tau)} \leq 1
$$

Assumption stands for the fact that, in reality, people who save their money in a given pension fund, but may leave it and obtain (a fraction of) their savings as they do it.

The main consequence of this change is that, instead of computing the actuarial present values as we did in Propositions, , and, we need to adjust the figures with the actuarial present values of the refunds as a part of the benefits purchased with the pension plan. We start the corresponding descriptions with the defined-contribution plans.

\subsection{Defined-contribution plans}

We assume that the value of ${ }^{d c} c^{\prime}$ the annual contribution rate of the salary is known, moreover, we denote by $u \in[0,1]$ to the fraction of the savings that a life is entitled to withdraw from the fund if it does not reach the age of retirement. We intend to find the value of ${ }^{d c} P^{\prime}$, that is, the income benefit rate for the pension.

We start by calculating the actuarial present value of the contributions under the hypothesis of portability. To this end, we state an analogous result to Proposition . Note that the consequence of using Assumption is the replacement of the certain annuity in (7) for a contingent one. Let ${ }^{d c} c^{\prime}$ be the annual contribution rate of the salary. Under Assumptions 2.1 and, the actuarial present value of the contributions made to the retirement plan for a life aged $(x)$ are given by:

$$
{ }^{d c}(A P V C)_{x}^{\prime}={ }^{d c} c^{\prime} \cdot(E S)_{x} \cdot \ddot{a}_{x}: y-x,
$$

where

$$
\ddot{a}_{x:} y-x:=\sum_{k=0}^{y-x-1}{ }_{k} p_{x}^{(\tau)}\left(\frac{1}{1+\gamma}\right)^{k} .
$$

As in Proposition, the actuarial present value of the contributions equals the sum of the actuarial present values of the periodic contributions. That is:

$$
\begin{aligned}
{ }^{d c}(A P V C)_{x}^{\prime}= & { }^{d c} c^{\prime} \cdot(E S)_{x}+{ }^{d c} c^{\prime} \cdot(E S)_{x+1} \frac{1}{1+r} \cdot p_{x}^{(\tau)}+{ }^{d c} c^{\prime} \cdot(E S)_{x+2}\left(\frac{1}{1+r}\right)^{2} \cdot{ }_{2} p_{x}^{(\tau)} \\
& +\cdots+{ }^{d c} c^{\prime} \cdot(E S)_{y-1}\left(\frac{1}{1+r}\right)^{y-x-1} \cdot{ }_{y-x-1} p_{x}^{(\tau)} \\
= & { }^{d c} c^{\prime} \cdot(E S)_{x} \cdot\left[1+\frac{1+s}{1+r} \cdot p_{x}^{(\tau)}+\left(\frac{1+s}{1+r}\right)^{2} \cdot{ }_{2} p_{x}^{(\tau)}+\cdots+\left(\frac{1+s}{1+r}\right)^{y-x-1} \cdot{ }_{y-x-1} p_{x}^{(\tau)}\right] .
\end{aligned}
$$

We owe the last equality to the use of Assumptions 2.1 and . A direct substitution of $\ddot{a}_{x}: y-x$ for the sum inside braces yields the result. Now we calculate the actuarial present value of the benefits under the hypothesis of portability. Under Assumptions 2.1 and, the actuarial present value of the benefits for a life aged $(x)$ is given by

${ }^{d c}(A P V B)_{x}^{\prime}=(E S)_{x}\left[{ }^{d c} P^{\prime} \cdot \ddot{a}_{y}\left(\frac{1}{1+\gamma}\right)^{y-x} \cdot{ }_{y-x} p_{x}^{(\tau)}+u \cdot{ }^{d c} c^{\prime} \cdot\left(\ddot{a}_{x}: y-x-{ }_{y-x} p_{x}^{(\tau)} \cdot \ddot{a} y-x\right)\right]$. 
Let ${ }^{d c}(A P V R)_{x}$ be the actuarial present value of the refunds for a life aged $(x)$. From (9) and (11), we readily know the origin of the first term inside the braces on the right-hand-side of (16). To prove the second term, observe that the actuarial present value of the refunds for a life aged $(x)$ is given by

$$
\begin{aligned}
{ }^{d c}(A P V R)_{x}= & u \cdot{ }^{d c} c^{\prime} \cdot(E S)_{x} \cdot{ }_{y-x} q_{x}^{(\tau)}+u \cdot{ }^{d c} c^{\prime} \cdot(E S)_{x+1} \cdot p_{x}^{(\tau)} \cdot{ }_{y-x-1} q_{x+1}^{(\tau)} \frac{1}{1+r} \\
& +u \cdot{ }^{d c} c^{\prime} \cdot(E S)_{x+2} \cdot{ }_{2} p_{x}^{(\tau)} \cdot{ }_{y-x-2} q_{x+2}^{(\tau)}\left(\frac{1}{1+r}\right)^{2}+\cdots \\
& +u \cdot{ }^{d c} c^{\prime} \cdot(E S)_{y-1} \cdot{ }_{y-x-1} p_{x}^{(\tau)} \cdot q_{y-1}^{(\tau)}\left(\frac{1}{1+r}\right)^{y-x-1} \\
= & u \cdot{ }^{d c} c^{\prime}(E S)_{x}\left[\left(1-{ }_{y-x} p_{x}^{(\tau)}\right)+\frac{1+s}{1+r} \cdot p_{x}^{(\tau)} \cdot\left(1-{ }_{y-x-1} p_{x+1}^{(\tau)}\right)\right. \\
& +\left(\frac{1+s}{1+r}\right)^{2} \cdot{ }_{2} p_{x}^{(\tau)} \cdot\left(1-{ }_{y-x-2} p_{x+2}^{(\tau)}\right)+\cdots \\
& \left.+\left(\frac{1+s}{1+r}\right)^{y-x-1} \cdot{ }_{y-x-1} p_{x}^{(\tau)} \cdot\left(1-p_{y-1}^{(\tau)}\right)\right] .
\end{aligned}
$$

For the second equality, we have used (2) and (6). Then, it is clear that

$$
\begin{aligned}
& { }^{d c}(A P V R)_{x}=u \cdot{ }^{d c} c^{\prime}(E S)_{x}\left[\ddot{a}_{x}: y-x-{ }_{y-x} p_{x}^{(\tau)} \sum_{k=0}^{y-x-1}\left(\frac{1}{1+\gamma}\right)^{k}\right] \\
& =u \cdot{ }^{d c} c^{\prime}(E S)_{x}\left(\ddot{a}_{x}: y-x-{ }_{y-x} p_{x}^{(\tau)} \cdot \ddot{a} y-x\right) .
\end{aligned}
$$

Since the actuarial present value of the benefits of a defined-contribution plan with the possibility of withdrawing the savings equals the pension benefits plus the expectation of the refunds, we have completed the proof. As a by-product of the proof of Proposition 4.3, it is worth to mention that, from (17)-(19), if ${ }_{y-x-k} p_{x+k}^{(\tau)} \equiv 1$ for $k=0, \ldots, y-x-1$ (that is, if Assumption holds instead of Assumption ), then

$$
{ }^{d c}(A P V B)_{x}={ }^{d c}(A P V B)_{x}^{\prime},
$$

that is, if leaving the group were impossible during the period of accrual of the pension fund, then the results of Propositions and 4.3 would be identical. We use Assumption 2.1(iii) to equal (14) and (16); and solve for the income benefit rate ${ }^{d c} P^{\prime}$ (resp. annual contribution rate of the salary ${ }^{d c} c^{\prime}$ ). Thus we obtain our following result. Under Assumptions 2.1 and, the benefit income rate and the annual contribution rate of the salary for a defined-contribution plan are given by

$$
\begin{aligned}
{ }^{d c} P^{\prime} & =\frac{{ }^{d c} c^{\prime} \cdot\left[u \cdot \ddot{a} y-x \cdot{ }_{y-x} p_{x}^{(\tau)}+(1-u) \ddot{a}_{x:} y-x\right]}{\left(\frac{1}{1+\gamma}\right)^{y-x} \cdot \ddot{a}_{y} \cdot{ }_{y-x} p_{x}^{(\tau)}}, \text { and } \\
{ }^{d c} c^{\prime} & =\frac{{ }^{d c} P^{\prime} \cdot\left(\frac{1}{1+\gamma}\right)^{y-x} \cdot{ }_{y-x} p_{x}^{(\tau)} \cdot \ddot{a}_{y}}{(1-u) \ddot{a}_{x:} y-x+u \cdot{ }_{y-x} p_{x}^{(\tau)} \cdot \ddot{a} y-x},
\end{aligned}
$$

respectively. 


\section{Two particular cases of interest}

For most of the (public) defined-contribution plans with portability, each person can take all his/her savings in the case that he/she decides to leave the collectivity before attaining the retirement age. That is, $u \equiv 1$. The following result is a direct consequence of Proposition 4.5 under this variant. Let $u=1$ and consider a defined-contribution plan. Under Assumptions 2.1 and , the benefit income rate ${ }^{d c} P_{1}^{\prime}$ and the annual contribution rate of the salary ${ }^{d c} c_{1}^{\prime}$ are given by

$$
\begin{aligned}
{ }^{d c} P_{1}^{\prime} & =\frac{{ }^{d c} c_{1}^{\prime} \cdot(1+\gamma)^{y-x} \cdot \ddot{a} y-x}{\ddot{a}_{y}}, \text { and } \\
{ }^{d c} c_{1}^{\prime} & =\frac{{ }^{d c} P_{1}^{\prime} \cdot \ddot{a}_{y}}{(1+\gamma)^{y-x} \cdot \ddot{a} y-x},
\end{aligned}
$$

respectively. The other case of our interest is the one where $u \equiv 0$. The reason is the existence of (private) institutions that manage individual pension funds which do not allow people to take their savings with them when they leave the fund. Our next result states expressions for the benefit income and the contribution rates under this hypothesis. Its proof is immediate from Proposition 4.5. Let $u=0$ and consider a defined-contribution plan. Under Assumptions 2.1 and , the benefit income rate ${ }^{d c} P_{0}^{\prime}$ and the annual contribution rate of the salary ${ }^{d c} c_{0}^{\prime}$ are given by

$$
\begin{aligned}
{ }^{d c} P_{0}^{\prime} & =\frac{{ }^{d c} c_{0}^{\prime} \cdot(1+\gamma)^{y-x} \cdot \ddot{a}_{x:} y-x}{\ddot{a}_{y} \cdot y-x} p_{x}^{(\tau)}, \text { and } \\
{ }^{d c} c_{0}^{\prime} & =\frac{{ }^{d c} P_{0}^{\prime} \cdot{ }_{y-x} p_{x}^{(\tau)} \cdot \ddot{a}_{y}}{(1+\gamma)^{y-x} \ddot{a}_{x:} y-x}
\end{aligned}
$$

respectively. The expressions derived from Corollary 4.7 are interesting in view of the fact that, since one is not supposed to withdraw any money in the eventuality of leaving the collectivity, the sellers of private pension plans consider a certain annuity $\ddot{a} y-x$ au lieu of the contingent annuity $\ddot{a}_{x}: y-x$. The result is that, since, under Assumption, $\ddot{a} y-x \geq \ddot{a}_{x}: y-x$, then

$$
\begin{aligned}
{ }^{d c} P_{0}^{\prime} & \leq \frac{{ }^{d c} c_{0}^{\prime} \cdot(1+\gamma)^{y-x} \cdot \ddot{a} y-x}{\ddot{a}_{y} \cdot y-x} p_{x}^{(\tau)} \\
{ }^{d c} c_{0}^{\prime} & \geq \frac{{ }^{d c} P_{0}^{\prime} \cdot{ }_{y-x} p_{x}^{(\tau)} \cdot \ddot{a}_{y}}{(1+\gamma)^{y-x} \ddot{a} y-x} .
\end{aligned}
$$

\subsection{Defined-benefit plans}

For a defined-benefit plan, let ${ }^{d b} P^{\prime}$ be the income benefit rate for the pension, and ${ }^{d b} c^{\prime}$ the annual contribution of the salary. Now we state analogous results to Propositions 4.3 and 4.2, respectively, under the hypothesis that people may leave the collectivity with portability benefits. The proofs are entirely analogous and therefore, we omit them. Under Assumptions 2.1 and, the actuarial present value of the benefits for a life aged $(x)$ is given by:

$$
{ }^{d b}(A P V B)_{x}^{\prime}=(E S)_{x}\left[{ }^{d b} P^{\prime} \cdot \ddot{a}_{y}\left(\frac{1}{1+\gamma}\right)^{y-x} \cdot{ }_{y-x} p_{x}^{(\tau)}+u \cdot{ }^{d b} c^{\prime}\left(\ddot{a}_{x}: y-x-{ }_{y-x} p_{x}^{(\tau)} \cdot \ddot{a} y-x\right)\right],
$$

again, $u \in[0,1]$ represents the fraction of the contribution that the person is entitled to take along with him/her should he/she leaves the fund. Let ${ }^{d b} c^{\prime}$ be the annual contribution rate of 
the salary. Under Assumptions 2.1 and, the actuarial present value of the contributions made to the retirement plan for a life aged $(x)$ is given by:

$$
{ }^{d b}(A P V C)_{x}^{\prime}={ }^{d b} c^{\prime} \cdot(E S)_{x} \cdot \ddot{a}_{x}: y-x .
$$

Propositions 4.8 and unveil the following analogue of Proposition 4.5. Under Assumptions 2.1 and , the benefit income rate and the annual contribution rate of the salary for a defined-benefit plan are given by

$$
\begin{aligned}
{ }^{d b} P^{\prime} & =\frac{{ }^{d b} c^{\prime} \cdot\left[u \cdot \ddot{a} y-x \cdot{ }_{y-x} p_{x}^{(\tau)}+(1-u) \ddot{a}_{x}: y-x\right]}{\left(\frac{1}{1+\gamma}\right)^{y-x} \cdot \ddot{a}_{y} \cdot{ }_{y-x} p_{x}^{(\tau)}}, \text { and } \\
{ }^{d b} c^{\prime} & =\frac{{ }^{d b} P^{\prime} \cdot\left(\frac{1}{1+\gamma}\right)^{y-x} \cdot{ }_{y-x} p_{x}^{(\tau)} \cdot \ddot{a}_{y}}{(1-u) \ddot{a}_{x:} y-x+u \cdot{ }_{y-x} p_{x}^{(\tau)} \cdot \ddot{a} y-x},
\end{aligned}
$$

respectively. We now present analogous results to Corollaries 4.6 and 4.7. Let $u=1$ and consider a defined-benefit plan. Under Assumptions 2.1 and, the benefit income rate and the annual contribution rate of the salary are given by

$$
\begin{aligned}
{ }^{d b} P_{1}^{\prime} & =\frac{{ }^{d b} c_{1}^{\prime} \cdot(1+\gamma)^{y-x} \cdot \ddot{a} y-x}{\ddot{a}_{y}}, \text { and } \\
{ }^{d b} c_{1}^{\prime} & =\frac{{ }^{d b} P_{1}^{\prime} \cdot \ddot{a}_{y}}{(1+\gamma)^{y-x} \cdot \ddot{a} y-x},
\end{aligned}
$$

respectively. Let $u=0$ and consider a defined-benefit plan. Under Assumptions 2.1 and, the benefit income rate and the annual contribution rate of the salary are given by

$$
\begin{aligned}
{ }^{d b} P_{0}^{\prime} & =\frac{{ }^{d b} c_{0}^{\prime} \cdot(1+\gamma)^{y-x} \cdot \ddot{a}_{x:} y-x}{\ddot{a}_{y} \cdot y-x} p_{x}^{(\tau)} \\
{ }^{d b} c_{0}^{\prime} & =\frac{{ }^{d b} P_{0}^{\prime} \cdot{ }_{y-x} p_{x}^{(\tau)} \cdot \ddot{a}_{y}}{(1+\gamma)^{y-x} \ddot{a}_{x:} y-x}
\end{aligned}
$$

respectively. Now we are ready to present the main result of this section. Let Assumptions 2.1 and hold. Then,

(i) A necessary and sufficient condition for ${ }^{d b} P={ }^{d c} P={ }^{d b} P_{1}^{\prime}={ }^{d c} P_{1}^{\prime}$ is ${ }^{d b} c={ }^{d c} c={ }^{d b} c_{1}^{\prime}={ }^{d c} c_{1}^{\prime}$.

(ii) A necessary and sufficient condition for ${ }^{d b} P^{\prime}={ }^{d c} P^{\prime}$ is ${ }^{d b} c^{\prime}={ }^{d c} c^{\prime}$.

(iii) A necessary and sufficient condition for

$$
{ }^{d b}(A P V B)_{x}^{\prime}={ }^{d c}(A P V B)_{x}^{\prime} \text { is }{ }^{d b}(A P V C)_{x}^{\prime}={ }^{d c}(A P V C)_{x}^{\prime} .
$$

(iv) ${ }^{d b} c_{0}^{\prime} \leq{ }^{d c} c_{1}^{\prime}$ when ${ }^{d b} P_{0}^{\prime}={ }^{d c} P_{1}^{\prime}$.

(i) We focus on the case where ${ }^{d b} P_{1}^{\prime}={ }^{d c} P_{1}^{\prime}={ }^{d c} P$ implies ${ }^{d b} c_{1}^{\prime}={ }^{d c} c_{1}^{\prime}={ }^{d c} c$, and its converse. The reason is that the case where ${ }^{d b} P={ }^{d c} P$ yields ${ }^{d b} c={ }^{d c} c$ (and its converse) is the statement of Theorem 3.9.

(Necessity.) Let $P:={ }^{d b} P_{1}^{\prime}={ }^{d c} P_{1}^{\prime}$. Substitute $P$ in the expressions for ${ }^{d c} c_{1}^{\prime}$ and ${ }^{d b} c_{1}^{\prime}$ in Corollaries 4.6 and 4.11, respectively. This yields ${ }^{d b} c_{1}^{\prime}={ }^{d c} c_{1}^{\prime}$.

Now let $P:={ }^{d c} P_{1}^{\prime}={ }^{d c} P$. Substitute $P$ in the expressions for ${ }^{d c} c$ and ${ }^{d c} c_{1}^{\prime}$ in Proposition and Corollary 4.6, respectively to see the desired implication.

(Sufficiency.) Let $c:={ }^{d b} c_{1}^{\prime}={ }^{d c} c_{1}^{\prime}$. Then Corollaries 4.6 and 4.11 yield ${ }^{d b} P_{1}^{\prime}={ }^{d c} P_{1}^{\prime}$.

Now let $c={ }^{d c} c_{1}^{\prime}={ }^{d c} c$. Substitute $c$ in the expressions for ${ }^{d c} P$ and ${ }^{d c} P_{1}^{\prime}$ in Proposition and Corollary 4.6, respectively to see that ${ }^{d c} P={ }^{d c} P_{1}^{\prime}$. 
(ii) To see that $P:={ }^{d b} P^{\prime}={ }^{d c} P^{\prime}$ implies ${ }^{d b} c^{\prime}={ }^{d c} c^{\prime}$, substitute $P$ in the expressions for ${ }^{d c} c^{\prime}$ and ${ }^{d b} c^{\prime}$ in Propositions 4.5 and 4.10, respectively. The proof of the converse is analogous.

(iii) The proof is immediate from Theorem 4.13(ii) and Propositions 4.2, 4.3, 4.8 and .

(iv) To see that ${ }^{d b} c_{0}^{\prime} \leq{ }^{d c} c_{1}^{\prime}$ when $P:={ }^{d b} P_{0}^{\prime}={ }^{d c} P_{1}^{\prime}$, we use Corollary 4.12 to write

$$
\begin{aligned}
{ }^{d b} c_{0}^{\prime} & =\frac{P \cdot{ }_{y-x} p_{x}^{(\tau)} \cdot \ddot{a}_{y}}{(1+\gamma)^{y-x} \ddot{a}_{x: y-x}} \\
& =\frac{P \cdot \ddot{a}_{y}}{(1+\gamma)^{y-x} \ddot{a}_{x:} y-x / y-x} p_{x}^{(\tau)}
\end{aligned}
$$

Now, by (15),

$$
\begin{aligned}
\frac{\ddot{a}_{x: y-x}}{{ }_{y-x} p_{x}^{(\tau)}} & =\frac{1}{{ }_{y-x} p_{x}^{(\tau)}}+\frac{1}{1+\gamma} \frac{p_{x}^{(\tau)}}{y-x} p_{x}^{(\tau)}+\cdots+\left(\frac{1}{1+\gamma}\right)^{y-x-1} \frac{{ }_{y-x-1} p_{x}^{(\tau)}}{y-x p_{x}^{(\tau)}} \\
& =\frac{1}{{ }_{y-x} p_{x}^{(\tau)}}+\frac{1}{1+\gamma} \frac{1}{y-x-1} p_{x+1}^{(\tau)}+\cdots+\left(\frac{1}{1+\gamma}\right)^{y-x-1} \frac{1}{p_{y-1}^{(\tau)}} \\
& \geq 1+\frac{1}{1+\gamma}+\cdots+\left(\frac{1}{1+\gamma}\right)^{y-x-1} \\
& =\ddot{a} y-x
\end{aligned}
$$

Here, (21) follows from (5); and (22), from (8). We apply the above inequality to (20), use Corollary 4.6, and write

$$
{ }^{d b} c_{0}^{\prime} \leq \frac{P \cdot \ddot{a}_{y}}{(1+\gamma)^{y-x} \ddot{a} y-x}:={ }^{d c} c_{1}^{\prime} .
$$

This proves the result.

The main implication of Theorem 4.13(i) is that, whether the people is allowed to leave the fund before attaining the retirement age (Assumption ), or not (Assumption ), the benefits/contributions are the same, given that the people is allowed to the possibility of a full portability. Now, the theory tell us that the fact that the costs of

- having a plan with no exits, i.e., with probability one of attaining the age of retirement (and therefore no portability), and

- having a plan with exits and full portability, i.e., with probability lower than one of attaining the age of retirement; but with the possibility of a full withdrawal

turn out to be equal is interesting from the point of view of a sales strategy. Indeed, the latter option is far more appealing forthe employee than the first, and it will cost the same for the entities who pay for the benefits (v.g. the employee and: the employer, the state, a pension institution, etc.).

Theorem 4.13(ii) delves in the case of a partial portability. It states that the contributions (resp. benefits) in either sort of plan are the same.

To the extent of our knowledge, Theorem 4.13(iii) represents the first effort to prove that the costs of both types of plans are equivalent. Observe, however, that we are letting Assumption 2.1(ii) hold. This means that we are assuming that no contributor will subsidize any other, from his/her generation or from any other.

Finally, the importance of Theorem 4.13(iv) is that it shows that a defined-contribution plan with full portability is more expensive than a defined-benefit plan with no portability at all. This is natural, because the benefit of the plan with full portability is also greater than that of the plan with no portability. 


\section{Group model}

In the last two sections we proved that, for a life aged $(x)$, the actuarial present values of the benefits (contributions) are equal, regardless of the type of plan under consideration. Now we intend to show that this assertion holds true for a collectivity of $\ell_{0}$ contributors in a closed group (recall Assumption (ii)), that is, where there are no new entries. Since we have departed from the individual context, and we intend to calculate the premia payable by them in order to match the risk that each one brings to a collectivity, the notion of actuarial fairness will pervade our focus.

\subsection{Defined-contribution plans}

For a group with a defined-benefit plan, it is only natural to use an aggregation method that consists in simply adding-up the individual obligations/contributions (without portability benefits)while maintaining the actuarial balance (see (Bowers y cols., 1997, Chapter 20.5) and (Collinson, 2001, Appendix 2)) for computing the actuarial present values involved in the computation:

$$
\begin{aligned}
{ }^{d c}(A P V C) & =\sum_{i=1}^{\ell_{0}} d c(A P V C)_{[x]_{i}}, \\
{ }^{d c}(A P V B) & =\sum_{i=1}^{\ell_{0}} d c(A P V B)_{[x]_{i}} ;
\end{aligned}
$$

and with portability benefits:

$$
\begin{aligned}
d c(A P V C)^{\prime} & =\sum_{i=1}^{\ell_{0}} d c(A P V C)_{[x]_{i}}^{\prime}, \\
{ }^{d c}(A P V B)^{\prime} & =\sum_{i=1}^{\ell_{0}} d c(A P V B)_{[x]_{i}}^{\prime} .
\end{aligned}
$$

Here and in the sequence, the sub-index $[x]_{i}$ stands for the fact that the $i$-th contributor in a group is a life aged $(x)$ at selection (see (Bowers y cols., 1997, Chapter 3.8)), and he/she ages from that age on, for $i=1,2, \ldots, \ell_{0}$.

\subsection{Defined-benefit plans}

We devote this section to the analysis of the so-called general average system (cf. (Bowers y cols., 1997, Chapter 20.8) , (Collinson, 2001, Appendix 2) and (Iyer, 1999, Chapter 1.7 and Appendix 3 )) for a defined-benefit plan. Now we do not assume that the group contributions are given by the sum of the individual contributions (therefore, (23) and (25) do not hold); it has been used by some pension systems in the United Kingdom and Ireland (see (Collinson, 2001, Appendices 1 and 2)), and is the standard in the Mexican Pension System (hence our interest on it).

\section{Defined-benefit without exits}

Now we analyze the case where there are no exits from the collectivity, and hence, there are no portability benefits. First, we define the actuarial present value of the contributions for a definedbenefit plan under the general average premium system (also known as aggregate methodology) when all the participants continue to contribute to the fund until the moment of their retirement, then we state an expression for the general average premium and prove that the actuarial present value of the aggregate contributions equals

$$
{ }^{d b}(A P V C):=\sum_{i=1}^{\ell_{0}} d b(A P V C)_{[x]_{i}} .
$$


Let the general average premium rate of contribution for a defined-benefit plan without exits (and therefore without any portability benefits) and no accrued reserves in a closed group be defined by

$$
{ }^{d b} \bar{c}:=\sum_{i=1}^{\ell_{0}} \frac{{ }^{d b}(A P V B)_{[x]_{i}}}{\sum_{j=1}^{\ell_{0}}(E S)_{[x]_{j}} \cdot \ddot{a} y-[x]_{j}} .
$$

We also define the actuarial present value of the total contributions under the aggregate methodology as

$$
{ }^{d b}(\overline{A P V C}):={ }^{d b} \bar{c} \cdot \sum_{i=1}^{\ell_{0}}(E S)_{[x]_{i}} \cdot \ddot{a} y-[x]_{i} .
$$

Observe that Definition uses Assumption 2.1(iii); mimics the proof of Proposition and aggregates the results. Indeed, by (28), we know that the actuarial present value of the aggregated benefits is given by

$$
\sum_{i=1}^{\ell_{0}} d b(A P V B)_{[x]_{i}}=\sum_{j=1}^{\ell_{0}} d b \bar{c} \cdot(E S)_{[x]_{j}} \cdot \ddot{a} y-[x]_{j} .
$$

In light of (29) and Assumption 2.1(iii), this means that

$$
{ }^{d b}(\overline{A P V C})=\sum_{i=1}^{\ell_{0}} d b(A P V B)_{[x]_{i}} ;
$$

which is an aggregation of the result found in Proposition .

Now we state an important result in terms of this methodology. Let Assumptions 2.1, 2 and hold. Then the general average premium rate of contribution for a defined-benefit plan without any portability benefits in a closed group is given by

$$
{ }^{d b} \bar{c}=\sum_{i=1}^{\ell_{0}} d b c^{i} \cdot \frac{(E S)_{[x]_{i}} \cdot \ddot{a} y-[x]_{i}}{\sum_{j=1}^{\ell_{0}}(E S)_{[x]_{j}} \cdot \ddot{a} y-[x]_{j}} .
$$

Moreover, for a defined-benefit plan, the actuarial present value of the total contributions under the aggregate methodology equals the sum displayed in (27) of the individual contributions computed in Proposition. That is,

$$
{ }^{d b}(\overline{A P V C})={ }^{d b}(A P V C) .
$$

To compute the general average premium rate of contribution ${ }^{d b} \bar{c}$ under the aggregate methodology for the defined-benefit scheme without any portability benefits, we start by taking advantage of the actuarial balance between the individual benefits (12) and the individual contributions (13), i.e.

$$
{ }^{d b}(A P V B)_{[x]_{i}}={ }^{d b} c^{i} \cdot(E S)_{[x]_{i}} \cdot \ddot{a} y-[x]_{i},
$$

where ${ }^{d b} c^{i}$ stands for the individual contribution rate of the $i$-th life, for $i=1, \ldots, \ell_{0}$. Now we aggregate the benefits of the participants of the collectivity:

$$
{ }^{d b}(A P V B)=\sum_{i=1}^{\ell_{0}} d b c^{i} \cdot(E S)_{[x]_{i}} \cdot \ddot{a} y-[x]_{i},
$$

We use Assumption 2.1(iii) to equate the actuarial present values in (29) and (32), and solve for ${ }^{d b} \bar{c}$. This yields (30).

The relation (31) follows immediately from substituting (30) in (29); and recalling (13) and (27). This proves the result. The interest of our characterization of the general average premium 
rate of contribution in (30) lies on the fact that, instead of viewing it as in (28) (i.e., an average of the benefits with respect to the salaries), it allows us to regard it as a weighted average of the individual contributions that each participant is to make in the individual context. However, there is no mathematical/financial condition to ensure that

$$
{ }^{d b} c^{i}={ }^{d b} \bar{c}
$$

for any $i=1,2, \ldots$ This means that, in practice some of the contributors will subsidize others. Besides, the expression (31) means that the present value of the cost of the aggregated contribution is the same, whether we compute it by adding-up the individual (fair) contributions, or by means of the general average premium rate of contribution. This implies that, from the point of view of the collectivity, the actuarial fairness principle is met.

This fact is of particular relevance when we consider it from the point of view of the entity who makes the contribution. In the case that the employer shares the responsibility with the employee, that is, if

$$
\begin{aligned}
{ }^{d b} c^{i} & =\alpha \cdot{ }^{d b} c^{i}+(1-\alpha) \cdot{ }^{d b} c^{i} \text { or } \\
{ }^{d b} \bar{c} & =\alpha \cdot{ }^{d b} \bar{c}+(1-\alpha) \cdot{ }^{d b} \bar{c},
\end{aligned}
$$

where $\alpha \in[0,1]$ is the fraction of the contribution paid by the employee, and $1-\alpha$ is the share of the employer, the expression (31) means that the cost is the same, regardless of the methodology chosen to pay for the individual contributions.

From the point of the employee, the expression (31) means that for the collectivity the cost of the aggregated pensions remains the same, regardless of the the methodology chosen to pay for the individual contributions. However, because of the subsidiarity among the contributors, the individual cost of a defined-benefit plan depends on the comparison between ${ }^{d b} c^{i}$ and ${ }^{d b} \bar{c}$ (for $i=1, \ldots, \ell_{0}$ ), even if the employer participates in funding a share of the pension.

\section{Defined-benefit with exits and portability benefits}

We start by recalling Assumption and the results shown in Section 4.2. In particular, we need Propositions 4.8 and. The following definition in analogous to Definition . Let the general average premium rate of contribution for a defined-benefit plan with exits and portability benefits in a closed group with $\ell_{0}$ members be defined by

$$
d b \bar{c}^{\prime}:=\sum_{i=1}^{\ell_{0}} \frac{{ }^{d b}(A P V B)_{[x]_{i}:}^{\prime}}{\sum_{j=1}^{\ell_{0}}(E S)_{[x]_{j}} \cdot \ddot{a}_{[x]_{j}:} y-[x]_{j}} .
$$

We also define the actuarial present value of the contributions as

$$
{ }^{d b}(\overline{A P V C})^{\prime}={ }^{d b} \bar{c}^{\prime} \sum_{i=1}^{\ell_{0}}(E S)_{[x]_{i}} \cdot \ddot{a}_{[x]_{i}:} y-[x]_{i} .
$$

As a tool to compute the actuarial present value of the total contribution in this scheme, we add-up the individual contributions (as computed in Proposition ) and define:

$$
{ }^{d b}(A P V C)^{\prime}:=\sum_{i=1}^{\ell_{0}} d b(A P V C)_{[x]_{i}}^{\prime} .
$$

This expression will serve us to state the following result, which is analogous to Proposition 5.2. However, we include its proof here for the sake of completeness. Let Assumptions 2.1, 2 and hold. Then the general average premium rate of contribution for a defined-benefit plan with portability benefits in a closed group is given by

$$
d b \bar{c}^{\prime}=\sum_{i=1}^{\ell_{0}} d b\left(c^{i}\right)^{\prime} \cdot \frac{(E S)_{[x]_{i}} \cdot \ddot{a}_{[x]_{i}:} y-[x]_{i}}{\sum_{j=1}^{\ell_{0}}(E S)_{[x]_{j}} \cdot \ddot{a}_{[x]_{j}:} y-[x]_{j}},
$$


where ${ }^{d b}\left(c^{i}\right)^{\prime}$ stands for the annual level contribution rate of the $i$-th life in the collectivity. Moreover, for a defined-benefit plan, the actuarial present value of the total contributions under the aggregate methodology equals the sum of the individual contributions. That is,

$$
{ }^{d b}(\overline{A P V C})^{\prime}={ }^{d b}(A P V C)^{\prime} .
$$

We profit from the balance between the individual contributions (14) and the individual benefits (16) exhibited in Assumption 2.1(iii) and write:

$$
{ }^{d c}(A P V B)_{[x]_{i}}^{\prime}={ }^{d c}\left(c^{i}\right)^{\prime} \cdot(E S)_{[x]_{i}} \cdot \ddot{a}_{[x]_{i}:} y-[x]_{i}
$$

for $i=1, \ldots, \ell_{0}$. Now we add-up all these terms, equate the resulting expression with (34), and solve for ${ }^{d c} \bar{c}^{\prime}$. This yields (36).

The relation (37) follows from substituting (36) in (34); and recalling (14) and (35). This proves the result. Since Proposition 5.5 is essentially identical to Proposition 5.2, the same arguments from Remark hold. As for the actuarial present value of the benefits with portability for the $i$-th contributor, Propositions 4.8 and 5.5 give:

${ }^{d b}(\overline{A P V B})_{[x]_{i}}^{\prime}:=(E S)_{[x]_{i}}\left[{ }^{d b} P_{i}^{\prime} \cdot \ddot{a}_{y}\left(\frac{1}{1+\gamma}\right)^{y-[x]_{i}} \cdot{ }_{y-[x]_{i}} p_{[x]_{i}}^{(\tau)}+u_{i} \cdot{ }^{d b} \bar{c}^{\prime} \cdot\left(\ddot{a}_{[x]_{i}}: y-[x]_{i}-{ }_{y-[x]_{i}} p_{[x]_{i}}^{(\tau)} \cdot \ddot{a} y-[x]_{i}\right)\right]$,

where $u_{i} \in[0,1]$ is the fraction of the savings that the employee is entitled to withdraw if he/she leaves the collectivity; and ${ }^{d b} P_{i}^{\prime}$ is the income benefit rate for the $i$-th contributor.

Now, since there is no argument to guarantee that ${ }^{d b} \bar{c}^{\prime}={ }^{d b}\left(c^{i}\right)^{\prime}$, we can not ensure either that

$$
{ }^{d b}(\overline{A P V B})_{[x]_{i}}^{\prime}={ }^{d b}(A P V B)_{[x]_{i}}^{\prime} .
$$

However, this means that, in view of the actuarial balance between (35) and (37), under the aggregate methodology, some employees will subsidize others.

Now we are ready to state the main result of this section.

(i) Let ${ }^{d c} P^{i}$ (resp. ${ }^{d b} P^{i}$ ) be the benefit income rate for the $i$-th contributor in a group with a defined-contribution (resp. defined-benefit) plan, for $i=1, \ldots, \ell_{0}$. If ${ }^{d c} P^{i}={ }^{d b} P^{i}$ for all $i=1, \ldots, \ell_{0}$, then ${ }^{d c}(A P V C)={ }^{d b}(\overline{A P V C})$.

(ii) Let ${ }^{d b}\left(P^{i}\right)^{\prime}$ (resp. $\left.{ }^{d c}\left(P^{i}\right)^{\prime}\right)$ be the benefit income rate for the $i$-th life in a group with a defined-benefit (resp. defined-contribution) plan with portability benefits, for $i=1, \ldots, \ell_{0}$. If ${ }^{d b}\left(P^{i}\right)^{\prime}={ }^{d c}\left(P^{i}\right)^{\prime}$ for all $i=1, \ldots, \ell_{0}$, then ${ }^{d c}(A P V C)^{\prime}={ }^{d b}(\overline{A P V C})^{\prime}$.

(i) If ${ }^{d c} P^{i}={ }^{d b} P^{i}$ for all $i=1, \ldots, \ell_{0}$, then by $(23)$,

$$
\begin{aligned}
{ }^{d c}(A P V C) & =\sum_{i=1}^{\ell_{0}} d c(A P V C)_{x_{i}} \\
& =\sum_{i=1}^{\ell_{0}} d b(A P V C)_{x_{i}} \text { (by Theorem 3.9(ii)) } \\
& =d b(\overline{A P V C})(\text { by }(31)) .
\end{aligned}
$$

(ii) Theorem 4.13(ii) ensures that, if ${ }^{d b}\left(P^{i}\right)^{\prime}={ }^{d c}\left(P^{i}\right)^{\prime}$, then $\left(c^{i}\right)^{\prime}:={ }^{d b}\left(c^{i}\right)^{\prime}={ }^{d c}\left(c^{i}\right)^{\prime}$ for all $i=1, \ldots, \ell_{0}$. Now, by $(25)$,

$$
\begin{aligned}
{ }^{d c}(A P V C)^{\prime} & =\sum_{i=1}^{\ell_{0}} d c(A P V C)_{x_{i}}^{\prime} \\
& =\sum_{i=1}^{\ell_{0}}\left(c^{i}\right)^{\prime} \cdot(E S)_{x_{i}} \cdot \ddot{a}_{x_{i}}: y-x_{i}(\text { by }(14)) .
\end{aligned}
$$


On the other hand, by (34)

$$
\begin{aligned}
d b(\overline{A P V C})^{\prime} & ={ }^{d b} \bar{c}^{\prime} \sum_{i=1}^{\ell_{0}}(E S)_{x_{i}} \cdot \ddot{a}_{x_{i}:} y-x_{i} \\
& =\sum_{i=1}^{\ell_{0}}\left(c^{i}\right)^{\prime} \cdot \frac{(E S)_{x_{i}} \cdot \ddot{a}_{x_{i}}: y-x_{i}}{\sum_{j=1}^{\ell_{0}}(E S)_{x_{j}} \cdot \ddot{a}_{x_{j}}: y-x_{j}} \cdot \sum_{i=1}^{\ell_{0}}(E S)_{x_{i}} \cdot \ddot{a}_{x_{i}:} y-x_{i} \text { (by (36)) } \\
& =d c(A P V C)^{\prime} .
\end{aligned}
$$

This proves the result. As a by-product of Theorem 5.6, we can ensure that if the employees share the responsibility of financing their pensions with another entity (for instance, their employer), who contributes with the same proportion to all the funds, then the cost will be shared according to that proportion.

Indeed, take the case of a pension plan with portability benefits. If

$$
d c\left(c^{i}\right)^{\prime}=\alpha \cdot d c\left(c^{i}\right)^{\prime}+(1-\alpha) \cdot d c\left(c^{i}\right)^{\prime} \text { for } i=1, \ldots, \ell_{0},
$$

where $\alpha$ is the fraction paid by the employee and $(1-\alpha)$ the one put by the other entity, then it is straightforward to see that

$$
{ }^{d c}(A P V C)^{\prime}=\alpha \cdot{ }^{d c}(A P V C)^{\prime}+(1-\alpha) \cdot{ }^{d c}(A P V C)^{\prime} .
$$

By Theorem 5.6(ii), we have that

- the following relation holds:

$$
{ }^{d b}(\overline{A P V C})^{\prime}=\alpha \cdot{ }^{d b}(\overline{A P V C})^{\prime}+(1-\alpha) \cdot{ }^{d b}(\overline{A P V C})^{\prime}, \text { and }
$$

- the employer will be indifferent as to the choice between the costs of a defined-benefit plan, and a defined-contribution plan.

\section{Conclusions}

In this work we followed the arguments in (Aguirre-Farías, 2012; Diamond, 2002; Iyer, 1999; Knell, 2017; Meneu y cols., 2016; Organisation for Economic Co-operation and Development y cols., 2014; Poterba y cols., 2007) to present an actuarial comparison of the defined-contribution and defined-benefit pension schemes under Assumptions 2.1, and ; and we proved that if both offer the same benefits, there are no accrued reserves (or if there are, they are equal in both cases), and we make the same biometric and financial assumptions for both schemes; then the incomes needed to finance each of them are equal.

All of our results are free of the main historical errors that are made when comparing these schemes. Namely

- Different amounts, requirements and conditions for earning the benefits are assumed in each scheme (see (Ali y Frank, 2019; Almeida y Fornia, 2009; Flores-Quiroz, 2007; Ilmanen y cols., 2017; Johnston y cols., 2001; Ortiz y cols., 2019; Robbins, 2018; Schrager, 2009; Williamson y cols., 2009; The World Bank, 1994)).

- An assumption on the defined-contribution schemes creating reserves by themselves (see (Flores-Quiroz, 2007; Milanés-García-Moreno, 2013; Robbins, 2018; Schrager, 2009; The World Bank, 1994)). 
We avoided the first problem by assuming, for both schemes the same (interest, and salary and pension growth) rates; and the same decrement and mortality probabilities for each stage of the lives of the contributors (i.e. the savings phase and the aging phase).

As for the second problem, it is important to state that, in real-life, the reserves are generated by breaking the so-called intergenerational solidarity, that is, the scheme is supposed to receive contributions and it will not have disbursements for pension expenses until three or four decades after, because the transition cost will be taken over by another administrator. Indeed, for a defined-benefit plan, the transition cost is normally assumed to be paid by the same fund to which the new generations of employees contribute, therefore it does not produce neither reserves, nor interests, which increases the cost of the required contributions. On the other hand, for the defined-contribution scheme, a standard assumption is that the reserves generate interests which might be used to pay the pension benefits; the impact of this hypothesis is a reduction of the required contributions. Evidently, under these circumstances, the comparison is not valid.

$5.5 \mathrm{~s} 3.9,4.13$ and 5.6 show that, if the benefits granted by both schemes are the same and have equal requirements to obtain them, then the cost is the same. Moreover, 5.5s 3.9 and 4.13 assert also a converse of this assertion when early retirements are not allowed, and when they are, respectively. In particular, by Theorem 4.13(i), we know that the cost of a plan with early retirements and full portability (that is, with probability lower than one of attaining the age of retirement) equals that of a plan without the possibility of an early retirement (that is, with probability one of attaining the age of retirement), regardless of the scheme we take into account. This is relevant from a commercial point of view, because a decision-maker might consider investing in a pension plan for his/her employees without the chance of an early retirement; but this variant is just as expensive as the more advantageous option (for the beneficiary) of a plan with full portability. On the other hand, Theorem 4.13(iv) yields that if the defined-contribution scheme adds early withdrawals or rollover as a benefit, then it turns out to be more expensive than a defined-benefit plan. To maintain the equality, it is necessary for the defined-benefit scheme to offer the same benefits, that is, the so-called lump-sum portability.

Theorem 3.9 uses Propositions - and our hypothesis on the actuarial balance (Assumption 2.1(iii)) to show that if there are no early retirements and the benefit granted as pension is the same under the defined-benefit and the defined-contribution schemes, then both plans cost the same. The converse is also true. Propositions and give explicit expressions for both, the benefit income rate, and the contribution rate for a defined-contribution plan and a defined-benefit plan, respectively. It is worth to note the fact that, since we are assuming that no early retirements are allowed during the phase of accrual of the contributor's life (Assumption ), we use the certain annuity-due expression given by (8). However, we use the whole-life contingent annuity-due (10) for the aging phase of the contributor's life to reflect the fact that the contributor stops to receive the pension when he/she dies. Propositions - and - give explicit expressions for the actuarial present values of the contributions and benefits for a life aged $(x)$ under a defined-contribution scheme, and a defined-benefit scheme, respectively.

Theorem 4.13(ii)-(iii) follows the same path than its predecessor (but with Propositions 4.24.3, 4.5, and 4.8-4.10, along with Corollaries 4.6 and 4.11) to show that if early retirements are allowed, the cost of a defined-benefit plan equals that of a defined-contribution plan (regardless of the proportion of the contribution that the contributor is entitled to withdraw with him/her). To the extent of our knowledge, this is the first time that such a comparison is made without making different assumptions on the pension schemes at hand.

The particular cases presented by Corollaries 4.6-4.7 and 4.11-4.12 use Assumption 2.1(iii) to give explicit expressions for the income and contribution rates for the schemes under consideration when early retirements are allowed but the portability is full, or null. These results are fundamental for some the context of some nations, for they represent the cases of the public pension plans (Corollaries 4.6 and 4.11) and the private pension plans (Corollaries 4.7 and 4.12).

Theorem 5.6 is the aggregated version of Theorems 3.9 and 4.13. It is important to state that, while for the defined-contribution scheme, the $i$-th person contributes to the fund with the 
amount ${ }^{d c} c^{i} \cdot(E S)_{[x]_{i}}$ when there are no early retirements $\left(\right.$ resp. $\left({ }^{d c} c^{i}\right)^{\prime} \cdot(E S)_{[x]_{i}}$, when earl contributes to the fund with the general average premium ${ }^{d b} \bar{c} \cdot(E S)_{[x]_{i}}$ when there are no early retirements (resp. $\left.\left({ }^{d b} \bar{c}^{i}\right)^{\prime} \cdot(E S)_{[x]_{i}}\right)$, when early retirements are allowed). The consequence is that, although the cost of either plan is the same for the collectivity (when equal benefits are offered to the contributors), the latter can be more or less expensive for the individuals. The reason is that there is no mathematical, financial or actuarial argument to state that

$$
\begin{aligned}
\left({ }^{d b} \bar{c}^{i}\right) & =\left({ }^{d b} c^{i}\right) \\
\text { (resp. }\left({ }^{d b} \bar{c}^{i}\right)^{\prime} & \left.=\left({ }^{d b} c^{i}\right)^{\prime}\right) .
\end{aligned}
$$

That is, since the general average premium rate is a weighted average of the individual contribution rates (Propositions 5.2 and 5.5), it is to be expected that some persons pay less than others to obtain certain benefit.

The proofs shown in this work are based on fixed and equal assumptions to calculate the benefits and costs of both schemes. However, we know that the only exogenous variables that can be modified through time are those related to the accrued interest from the reserves or funds, the survival years after retirement, and the future behavior of the pensionable salary. Therefore, in order to dampen its effect and try to maintain or approximate the actuarial balance from Assumption 2.1(iii), it is recommendable to use adjustment factors in the defined-benefit scheme. Among them, our professional experience allows us to quote the following (see (Aguirre-Farías, 2001, 2012; Denuit, Haberman, y Renshaw, 2015; Meneu y cols., 2016)):

- Establishment of a retirement age that varies according to changes in life expectancy, or of a proportional modification of the pension amount.

- Application of a mechanism that modifies the pension amount or the retirement age depending on the variation of the accrued interests.

- Setting up a pensionable salary as a weighted average of the salaries that the employee received during his/her complete working life.

Considering the particularities indicated in this work, our main conclusion is the equality of the costs of the defined-benefit and defined-contribution schemes, when both intend to grant the same individual benefits, and the financial and biometric conditions are equivalent. So the discussion on which scheme is more expensive should be dropped. As Aguirre-Farías emphasizes (see (Aguirre-Farías, 2012)), the important thing is the negotiation and implementation of reforms to the pension systems in order to guarantee the quality of life of the pensioners, while maintaining the estimated future expending at reasonable levels and balancing the incomes and the expected expenses. 


\section{Referencias}

Aguirre-Farías, F. (2001). Diseño conceptual del método de las primas óptimas de liquidez. Aguascalientes, México: Instituto Nacional de Geografía y Estadística.

Aguirre-Farías, F. (2012). Pensiones... ¿̇y con qué? México: Fineo.

Ali, S., y Frank, H. (2019). Retirement planning decisions: Choices between defined benefit and defined contribution plans. The American Review of Public Administration, 49(2), 218-235. doi: 10.1177/0275074018765809

Almeida, B., y Fornia, W. (2009). Defined benefit plans: a better bang for the buck. Journal of Pension Benefits, 16(1), 11-15. (Retrieved from: https://www.nirsonline.org/wp -content/uploads/2017/07/journal_article_on_bang_for_buck.pdf)

Barr, N. (2002). Reforming pensions: Myths, truth, and policy choices. Int. Soc. Sec. Rev., 55(2), 3-37. doi: 10.1111/1468-246X.00122

Bowers, N., Gerber, H., Hickman, J., Jones, D., y Nesbitt, C. (1997). Actuarial mathematics. Schaumburg, Illinois: The Society of Actuaries.

Bräutigam, M., Guillen, M., y Nielsen, J. (2017). Facing up to longevity with old actuarial methods: a comparison of pooled funds and income tontines. Geneva Pap. Risk Insur. Issues Pract., 42(3), 406-422. doi: 10.1057/s41288-017-0056-1

Collinson, D. (2001). Actuarial methods and assumptions used in the valuation of retirement benefits in the eu and other european countries. Oxford, UK: Groupe Consultatif Actuariel Europeen.

Cunningham, R., Herzog, T., y London, R. (2006). Models for quantifying risk. Winsted, Connecticut: Actex Publications, Inc.

Denuit, M., Haberman, S., y Renshaw, A. (2015). Longevity-contingent deferred life annuities. Journal of Pension Economics and Finance, 14(3), 315-327. doi: 10.1017/ S147474721400050X

Diamond, P. (2002). Social security reform. Oxford, UK: Oxford University Press.

Donnelly, C. (2015). Actuarial fairness and solidarity in pooled annuity funds. Astin Bulletin, 45(1), 49-74. doi: 10.1017/asb.2014.18

Flores-Quiroz, M. (2007). Planes privados de pensiones y sus efectos en las empresas. México: Instituto Mexicano de Ejecutivos de Finanzas A.C. (Retrieved from: http://www.imef . org.mx/publicaciones/boletinestecnicosorig/BOL_28_04_CTN_SS.PDF)

Ilmanen, A., Kabiller, D., Siegel, L., y Sullivan, R. (2017). Defined contribution retirement plans should look and feel more like defined benefit plans. The Journal of Portfolio, 43(2), 61-76. doi: $10.3905 / \mathrm{jpm} .2017 .43 .2 .061$

Instituto Nacional de las Personas Adultas Mayores. (2017). Los beneficios de las relaciones intergeneracionales en las personas adultas mayores.

(Retrieved from: https://www.gob.mx/inapam/articulos/los-beneficios-de-las -relaciones-intergeneracionales-en-las-personas-adultas-mayores)

Iyer, S. (1999). Actuarial mathematics of social security pensions. Geneva, Switzerland: International Labour Organization.

Johnston, K., Forbes, S., y Hatem, J. (2001). Choosing between defined benefit and defined contribution plans. Journal of Financial Planning, 14(8), 86-98. (Retrieved from: https: //search.proquest. com/docview/217550632?accountid=26252)

Kellison, S. (2008). The theory of interest. London, UK: McGraw-Hill/Irwin.

Knell, M. (2017). Actuarial deductions for early retirement. Working Papers 215, Austrian Central Bank. (Retrieved from: https://www.oenb.at/dam/jcr:78999490-a990-449a $-80 \mathrm{f} 0-0 \mathrm{e} 1 \mathrm{e} 6611575 \mathrm{~d} / \mathrm{WP} 215 . \mathrm{pdf})$

Landes, X. (2015). How fair is actuarial fairness? J. Bus. Ethics, 128, 519-533. (Retrieved from: https ://doi.org/10.1007/s10551-014-2120-0) doi: 10.1007/s10551-014-2120-0

Meneu, R., Devesa, E., Devesa, M., Domínguez, I., y Encinas, B. (2016). Adjustment mechanisms 
and intergenerational actuarial neutrality in pension reforms. Int. Soc. Sec. Rev., 69, 87107. doi: 10.1111 issr. 12096

Milanés-García-Moreno, S. (2013). El eterno debate: beneficio definido vs. contribución definida.

(Retrieved from: http://bufetematematico.com/wp-content/uploads/2013/08/ definidocontribucion.pdf)

Organisation for Economic Co-operation and Development. (2015). Oecd reviews of pension systems: Mexico. OECD Publishing. (Retrieved from: https://www.oecd.org/mexico/ oecd-reviews-of-pension-systems-mexico-9789264245938-en.htm)

Organisation for Economic Co-operation and Development, Banco Interamericano de Desarrollo, y The World Bank. (2014). Pensions at a glance: Latin america and the caribbean. OECD Publishing. (Retrieved from: http://www.oecd.org/publications/oecd-pensions-at -a-glance-pension-glance-2014-en.htm)

Ortiz, I., Durán-Valverde, F., Urban, S., Wodsak, V., y Yu, Z. (2019). La reversión de la privatización de las pensiones: Reconstruyendo los sistemas públicos de pensiones en los países de europa oriental y américa latina (2000-2018). Geneva, Switzerland: International Labour Organization. (Retrieved from: https://www.social-protection.org/ gimi/RessourcePDF . action?id=55496)

Poterba, J., Rauh, J., Venti, S., y Wise, D. (2007). Defined contribution plans, defined benefit plans, and the accumulation of retirement wealth. J. Public. Econ., 91(10), 2062-2086. doi: $10.1016 /$ j.jpubeco.2007.08.004

Robbins, J. (2018). What is the difference between a defined benefit plan and a defined contribution plan?

(Retrieved from: http://time.com/money/collection-post/2791222/difference -between-defined-benefit-plan-and-defined-contribution-plan/)

Schrager, A. (2009). The decline of defined benefit plans and job tenure. Journal of Pension Economics and Finance, 8(3), 259-290. doi: 10.1017/S1474747208003570

Senado de la República. Coordinación de Comunicación Social. (2016a). Versión estenográfica de la ceremonia de inauguración de la semana de la seguridad social en el senado "panorama de las pensiones en méxico".

(Retrieved from: http://comunicacion.senado.gob.mx/index.php/informacion/ versiones/28152-version-estenografica-de-la-ceremonia-de-inauguracion-de -la-semana-de-la-seguridad-social-en-el-senado-panorama-de-las-pensiones -en-mexico.html)

Senado de la República. Coordinación de Comunicación Social. (2016b). Versón estenográfica de la comparecencia del presidente de la comisión nacional del sistema de ahorro para el retiro (primera parte).

(Retrieved from: http://comunicacion.senado.gob.mx/index.php/informacion/ versiones/32525-version-estenografica-de-la-comparecencia-del-presidente -de-la-comision-nacional-del-sistema-de-ahorro-para-el-retiro-primera -parte.html)

The World Bank. (1994). Averting the old age crisis: policies to protect the old and promote growth. Washington, D.C.: Oxford University Press.

Williamson, J., Shen, C., y Yang, Y. (2009). Which pension model holds the most promise for china: a funded defined contribution scheme, a notional defined contribution scheme or a universal social pension? Benefits, 17(2), 101-111. (Retrieved from: https://www2.bc .edu/john-williamson/documents/whichpensionmodel1.pdf) 